\section{Public Health Genomics}

Public Health Genomics 2012;15:57-72

DOI: $\underline{10.1159 / 000330403}$
Received: October 27, 2010

Accepted after revision: June 28, 2011 Published online: September 13, 201

\title{
Skin Cancer Concerns and Genetic Risk Information-Seeking in Primary Care
}

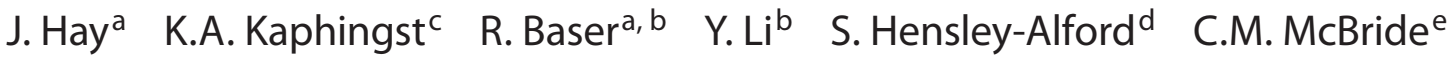 \\ Departments of a Psychiatry and Behavioral Sciences, and ${ }^{b}$ Epidemiology and Biostatistics, Memorial \\ Sloan-Kettering Cancer Center, New York, N.Y., 'Division of Public Health Sciences, Department of Surgery, \\ Washington University School of Medicine, St. Louis, Mo., ${ }^{\text {}}$ Henry Ford Hospital, Detroit, Mich., and \\ eNational Human Genome Research Institute, Washington, D.C., USA
}

\section{Key Words}

Genetic information · Skin cancer concerns

\begin{abstract}
Background: Genomic testing for common genetic variants associated with skin cancer risk could enable personalized risk feedback to motivate skin cancer screening and sun protection. Methods: In a cross-sectional study, we investigated whether skin cancer cognitions and behavioral factors, sociodemographics, family factors, and health informationseeking were related to perceived importance of learning about how (a) genes and (b) health habits affect personal health risks using classification and regression trees (CART). Results: The sample $(n=1,772)$ was collected in a large health maintenance organization as part of the Multiplex Initiative, ranged in age from $25-40$, was 53\% female, $41 \%$ Caucasian, and 59\% African-American. Most reported that they placed somewhat to very high importance on learning about how genes (79\%) and health habits $(88 \%)$ affect their health risks. Social influence actors were associated with information-seeking about genes and health habits. Awareness of family history was associated with importance of health habit, but not genetic, information-seeking. Conclusions: The investment of family and friends in health promotion may be
\end{abstract}

a primary motivator for prioritizing information-seeking about how genes and health habits affect personal health risks and may contribute to the personal value, or personal utility, of risk information. Individuals who seek such risk information may be receptive to interventions aimed to maximize the social implications of healthy lifestyle change to reduce their health risks.

Copyright $\odot 2011$ S. Karger AG, Basel

\section{Introduction}

Over the past 10 years, the sequencing of the entire human genome [1] has led to a rapid increase in our understanding of the genetics of cancer. These developments suggest the potential for personalized genomic susceptibility information to aid in the prevention and control of many common malignancies [2]. The isolation of high-risk inherited mutations in tumor suppressor genes has led to genetic information and testing for several uncommon hereditary cancer syndromes, including, but not limited to, retinoblastoma, Li-Fraumeni Syndrome and hereditary breast/ovarian and colorectal cancers. Psychosocial research on patient responses to these developments in the genetics and genomics of can-

\section{KARGER}

Fax +4161306 1234

E-Mail karger@karger.ch

www.karger.com (c) 2011 S. Karger AG, Basel

Accessible online at: www.karger.com/phg
Jennifer Hay

Department of Psychiatry and Behavioral Sciences

Memorial Sloan-Kettering Cancer Center, 641 Lexington Avenue

New York, NY 10022 (USA)

Tel. +1 646888 0039, E-Mail hayj@mskcc.org 
cer has been primarily focused on high-risk families who present in cancer specialty clinics where patients receive intensive genetic counseling [3, 4]. However, it is unclear whether we can generalize findings from high-risk families to the asymptomatic population at large, which is expected to be a primary target group for personalized genomics $[2,5]$. In the coming years, information about genetic susceptibility to cancer will be disseminated widely by mass media outlets and likely will increase awareness and information-seeking about genetic contributions to disease risk as well as demand for genetic testing in the general population [6]. Knowledge of the characteristics of the earliest information-seekers regarding genomic susceptibility information, and the range of motivations for seeking this information, will be helpful in anticipating opportunities and challenges in developing educational and decision-support programs for these populations.

Genomic information-seeking among those with skin cancer concerns represents an important context to explore these issues [7]. Skin cancers represent some of the most rapidly increasing cancers in the United States [8]. Melanoma, the most serious form of skin cancer, is the second most frequent cancer diagnosis among young women age 24-35 [9]. Incidence rates also continue to rise among many general population subgroups, including those of lower socioeconomic status [10,11]. Across nonCaucasian subgroups, melanoma tends to result in greater morbidity and mortality because the disease is often identified at later, less treatable stages and because of low physician and patient awareness that melanomas do occur in these populations [12-14]. The most common cutaneous melanoma subtype in African-Americans, acral lentiginous melanoma, has a lower survival rate than other melanomas [15]. There is strong evidence that both genetic factors (very rare, highly penetrant mutations such as CDKN2A and common, low-penetrant genetic variants) and environmental ultraviolet exposure contribute to risk for development of melanoma [16-18]. In the near future, genomic susceptibility testing concerning one or more common, low-penetrant variants for skin cancer may become available to the general population. For example, the melanocortin receptor gene (MC1R) interacts with sun exposure to heighten melanoma risk in the general population [19] including among African-Americans [20], making delivery of $M C 1 R$ testing an ideal prototype for exploring translation opportunities and challenges.

The Multiplex Initiative is a collaborative effort stemming from the National Human Genome Research Insti- tute and several sites of the Cancer Research Network, including the Henry Ford Health System in Detroit, Michigan and the Group Health Research Institute in Seattle, Washington. The Initiative was formed to assess factors influencing uptake of multiplex (multiple common genetic variants) genomic susceptibility testing for 8 common health conditions in a large managed care organization. For this study, patients were excluded if they had ever been diagnosed with diabetes, cardiovascular disease, osteoporosis, or cancer. The study oversampled hard-to-reach groups including African-Americans, men and those with low educational attainment [21].

In this report, we examine cross-sectional baseline data from the study to identify population subgroups who may be most likely to be 'early responders' in terms of interest in seeking personalized genomic susceptibility information. Individuals who have greater perceived risk and worry about skin cancer may be prime targets for direct-to-consumer marketing of cancer genetic tests, but little is known about whether those with heightened concerns about skin cancer place a heightened priority on information-seeking about how genetics or health habits contribute to their health risks. Understanding the skin cancer-related concerns of those who may pursue genetic testing would enhance our ability to develop relevant educational materials to improve individuals' evaluations of the personal and clinical utility of genetic testing information for skin cancer and other diseases, and to develop interventions that would maximize the psychosocial and health behavioral ramifications of such testing. Towards these ends, the goal of this National Human Genome Research Institute multiplex data analytic project is to identify skin cancer-salient factors related to motivation to learn about genetics and health habits. We use classification and regression trees (CART) [22] to identify predictors of importance of learning about genes and health habits among Caucasian and African-American participants. The CART strategy was developed to segment target audiences for product marketing [23] and is thus an ideal way to identify participant subgroups that share critical barriers or facilitators to genetic and healthhabit information-seeking in the current study that will enhance future intervention development.

Our first research question assesses whether skin cancer cognitive factors (skin cancer-perceived risk, skin cancer worry, genetic and health habit attributions for skin cancer) relate to perceived importance of learning about how genes affect personal health risks. Our second research question assesses whether skin cancer behavioral factors (sunburn, lack of sunscreen use) or motivations 
to improve health (reduce sun exposure or improve general health habits) relate to interest in learning about how genes affect personal health risks. Consistent with the Risk Information Seeking and Processing Model [24], we will also consider the role of sociodemographic variables (age, sex, education, marital and parenthood status), family factors (family health history awareness, family cancer history, social influences on health information-seeking) and frequency of health information-seeking as potential covariates of the findings.

Given that genetic susceptibility risk feedback has been regarded as a potential motivational tool to promote adherence to risk-reducing health habits, we examine parallel questions for health-habit information-seeking. Accordingly, our third research question assesses whether skin cancer cognitive factors relate to perceived importance of learning about how health habits affect personal health risks, and our fourth research question assesses whether skin cancer behavioral factors or motivations to improve health relate to interest in learning about how health habits affect personal health risks. Again consistent with the Risk Information Seeking and Processing Model [24], we will also consider the role of sociodemographic variables, family factors and frequency of health information-seeking as potential covariates of the findings.

\section{Methods}

\section{Study Sample}

The sampling frame for the study was a pool of 350,000 members of a large Midwestern health maintenance organization. The sample includes members between the ages of 25 and 40 , enrolled for at least 2 years, assigned to a primary care physician, and who had not been diagnosed with diabetes mellitus, atherosclerotic cardiovascular disease, osteoporosis, or cancer. A random sample of members who matched the selection criteria was drawn, oversampling for groups that have traditionally been underrepresented in genetic research (i.e. men, African-Americans and individuals living in areas where more than $10 \%$ of residents had low levels of education as determined by US census data). Sampling strategies are described in more detail elsewhere [25]. As reported previously [21], baseline surveys were attempted with 6,348 individuals; 2,614 were unreachable despite up to 10 repeated attempts, 1,292 declined to participate and 483 were found to be ineligible during screening or during the survey (they had been diagnosed with one of the health conditions). The baseline survey was completed by 1,959 participants.

The present study is based on data from the baseline screening call completed with 732 Caucasians and 1,040 African-Americans $(n=1,772)$; we excluded 187 who reported their race/ethnicity as 'other.'

\section{Data Collection Procedure}

An advance letter including a USD 2 bill was sent to sampled individuals explaining the study and providing a toll-free number to decline participation in a baseline screening call. During this baseline call, which was not introduced as related to genetics, participants answered questions related to their family and personal history of disease, beliefs and knowledge about genetics and health habits, and perceptions and beliefs related to common health conditions. Those who completed this call were later offered genetic testing and feedback on genetic susceptibility for 8 common health conditions (i.e. colon, skin and lung cancers, heart disease, osteoporosis, diabetes, high blood pressure, high cholesterol). Recruitment occurred from February 2007 to May 2008.

\section{Measures}

Outcome Variables

The 2 outcome variables in this study were derived from responses to 2 questions from the baseline survey. Specifically, the question pertaining to importance of learning about how genes affect health risks was, 'On a scale from 1 to 7 where 1 is 'not at all important' and 7 is 'very important', how important is it to you to learn more about how your genes, that is the characteristics that are passed from one generation to the next, affect your chance of getting certain health conditions?' The question pertaining to importance of learning about how health habits affect health risks was, 'On a scale from 1 to 7 where 1 is 'not at all important' and 7 is 'very important', how important is it to you to learn more about how your health habits affect your chance of getting certain health conditions?' Our 2 outcome variables were highly correlated $r=0.69$.

Predictor Variables

Predictor variables included skin cancer cognitive factors (skin cancer worry and perceived risk, level of agreement that (a) genes and (b) health habits cause skin cancer) and skin cancer behavioral factors (sunburn and sunscreen use history, motivation for future sun exposure reduction, motivation to improve general health habits). We also examined sociodemographics (age, sex, education, marital and parenthood status), family factors (family health history awareness, family cancer history, social influences on (a) learning more about health, (b) doing more about their health, (c) motivation to change health, and (d) health choices affecting others) and frequency of health informationseeking. Outcome and predictor variable names and descriptions are detailed in table 1.

\section{Statistical Methods}

Sociodemographics and responses to skin cancer cognitive and behavioral factor variables were cross-tabulated by racial/ ethnic group (African-American versus Caucasian, see tables 2, 3). Significant differences between the 2 racial/ethnic groups were tested using independent samples t tests on continuous variables, $\chi^{2}$ tests on categorical variables and Fisher's exact tests on dichotomous variables.

\section{Classification Trees}

We used CART [22] to identify predictors of importance of learning about genes and health habits among Caucasian and African-American participants. The CART approach is a popular data-mining technique [26] to stratify subjects into increasingly homogeneous subgroups, where members within the subgroups 


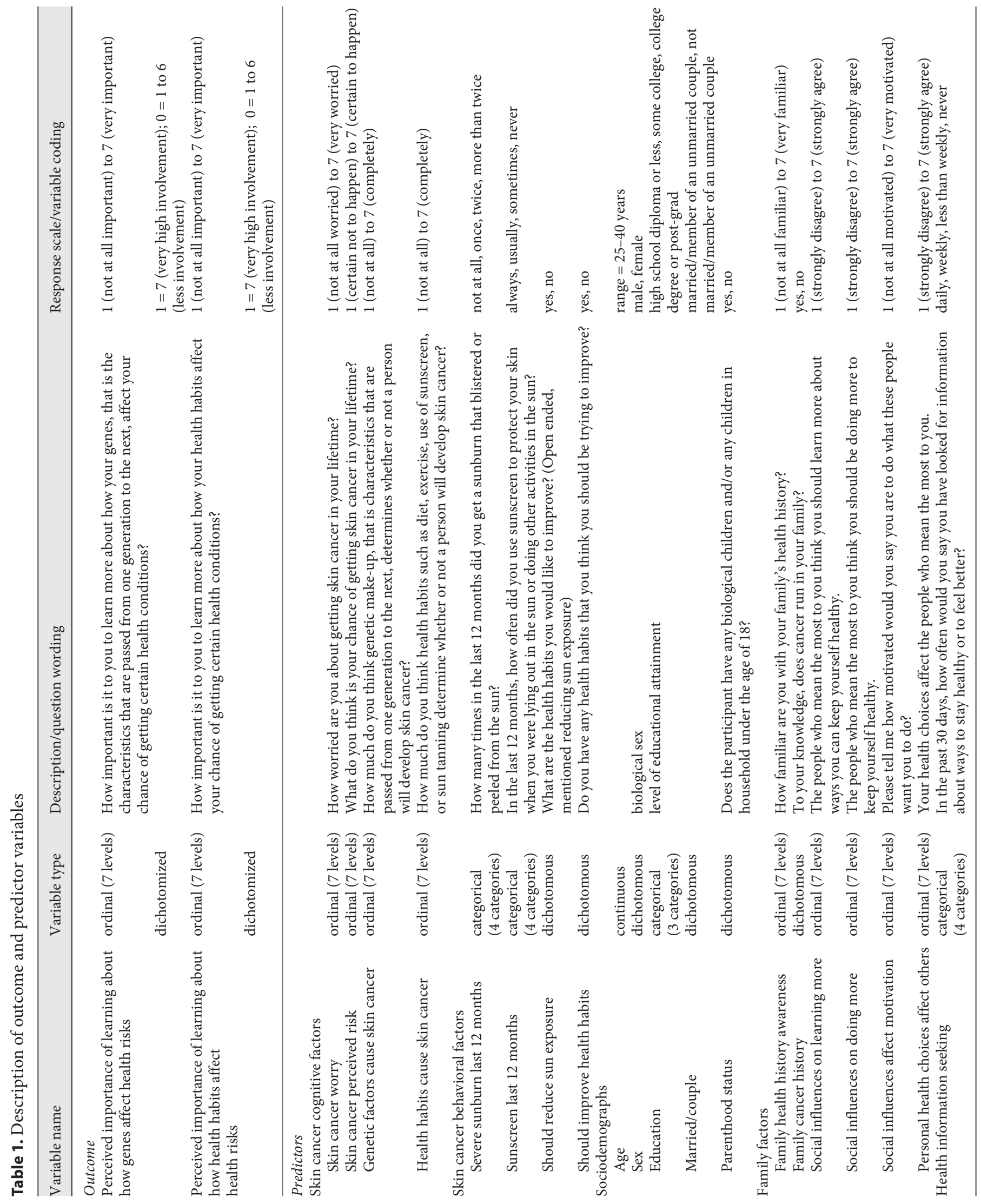


Table 2. Sociodemographic characteristics by race

\begin{tabular}{|c|c|c|c|c|}
\hline & Characteristic & $\begin{array}{l}\text { Caucasians } \\
(\mathrm{n}=732)\end{array}$ & $\begin{array}{l}\text { African-Americans } \\
(\mathrm{n}=1,040)\end{array}$ & $\mathrm{p}$ value \\
\hline Age & $\begin{array}{l}\text { Mean } \pm \text { SD } \\
\text { Median }\end{array}$ & $\begin{array}{l}34.6 \pm 4.2 \\
36\end{array}$ & $\begin{array}{l}34.6 \pm 4.1 \\
35\end{array}$ & 0.90 \\
\hline Sex & $\begin{array}{l}\text { Male } \\
\text { Female }\end{array}$ & $\begin{array}{l}350(47.81 \%) \\
382(52.19 \%)\end{array}$ & $\begin{array}{l}476(45.77 \%) \\
564(54.23 \%) \\
\end{array}$ & 0.40 \\
\hline Education & $\begin{array}{l}\text { High school diploma or less } \\
\text { Some college } \\
\text { College degree, post-grad }\end{array}$ & $\begin{array}{l}154(21.04 \%) \\
225(30.74 \%) \\
353(48.22 \%)\end{array}$ & $\begin{array}{l}283(27.21 \%) \\
432(41.54 \%) \\
321(30.87 \%)\end{array}$ & $<0.001$ \\
\hline Married/couple & $\begin{array}{l}\text { No } \\
\text { Yes }\end{array}$ & $\begin{array}{l}558(76.23 \%) \\
174(23.77 \%) \\
\end{array}$ & $\begin{array}{l}563(54.13 \%) \\
475(45.67 \%)\end{array}$ & $<0.001$ \\
\hline Parenthood status & $\begin{array}{l}\text { No } \\
\text { Yes }\end{array}$ & $\begin{array}{l}514(70.22 \%) \\
218(29.78 \%)\end{array}$ & $\begin{array}{l}820(78.85 \%) \\
220(21.15 \%)\end{array}$ & $<0.001$ \\
\hline
\end{tabular}

The $\mathrm{p}$ value for age is based on an independent samples $\mathrm{t}$ test with 1,770 degrees of freedom. All other $\mathrm{p}$ values are based on $\chi^{2}$ tests with either 2 (education) or 1 (all other variables) degrees of freedom.

are maximally similar and members across different subgroups are maximally dissimilar. For example, CART could identify that high-sunscreen users tend to be women who are physically active, between the ages of 25 and 45, allowing for the development of targeted sun protection messages for both high- and lower-sunscreen users with concrete information concerning user characteristics.

The CART approach has several practical and computational advantages. First, it is nonparametric and especially useful in capturing complex interactions between predictors [23]. Second, no assumptions need to be made regarding the underlying distributions of the predictor variables [27]. Third, CART can accommodate continuous predictor variables that are highly skewed and/or multi-modal as well as categorical predictors that may have ordinal or nonordinal structure. The CART approach has been used in marketing [28], public health [29-31] and cancer control research $[23,32,33]$. For example, using CART, Lemon et al. [23] identified subgroups of cancer patients whose surgical decisions were driven by similar psychosocial factors. In the current study, we used the Recursive PARTitioning (rpart) package in the statistical language $\mathrm{R}$ to carry out the CART calculations [34]. The rpart algorithm searches for the one best possible binary split of the full sample based on all possible cut points of the predictor variables and then partitions the full sample into 2 subsamples [35]. The result of this first split is often represented visually as a tree splitting the full sample into 2 child subsamples. The algorithm is repeated recursively until a prespecified limit on the minimal number of observations within the child subsample is met. At each split, the rpart program evaluates reduction in 'impurity' (using the Gini index, a measure of group heterogeneity, higher Gini values represent high heterogeneity or 'impurity') from the parent sample to the 2 child subsamples. The resulting partitioning tree is often called a 'full tree'. Variables closer to the top of the tree play a relatively more important role in prediction.

After a full tree is grown as described above, simplifications of the tree (or 'pruning') can be done to eliminate splits that result in too small a group and may thus be less reliable. The purpose of pruning is to both simplify the interpretation of the tree as well as to arrive at a tree that is more likely to generalize to other samples while retaining classification accuracy of the full tree $[35,36]$. Pruning can be accomplished by increasing the complexity parameter $(\mathrm{CP})$, which is a measure of how much additional accuracy a split must add to the entire tree to warrant the additional tree complexity $[34,35,37]$.

Our full trees were grown using these default values in rpart: (a) splits were not attempted in nodes with less than 20 observations, (b) Gini index was the split criterion, (c) terminal nodes were required to have at least 7 observations, and (d) misclassification losses were equal for each of the 2 classes within a given tree. For tree pruning, we used the plotcp () command in rpart to plot the cross-validation errors from the starting value of $\mathrm{CP}=$ 0.01 to the highest CP associated with the whole sample without segmentation (the root node without splits). The plotcp() command also plots the standard errors of the cross-validated costs, thereby giving us a guide in setting the optimal CP for pruning.

Finally, model performance was evaluated by comparing the model-predicted classification to the actual classification of each respondent and computing the total classification accuracy. We compared the model performance of the classification trees with the results of comparable logistic regression models (backwards selection eliminating all predictors until all those remaining were significantly related to the outcome at the $\mathrm{p}<0.05$ significance level).

\section{Results}

\section{Descriptive Statistics}

Sociodemographic characteristics of the sample are presented by racial/ethnic group (see table 2 ). The mean age of both Caucasians and African-Americans was 34.6 
years; approximately $52 \%$ of Caucasians and $54 \%$ of African-Americans were female. Caucasians tended to be more educated, less likely to be married or in a couple, and more likely to have children.

There were high levels of skew in the primary outcome variables, such that $22 \%$ of Caucasians and $43 \%$ of African-Americans reported highest levels of importance in learning about how genes affect health risks; $24 \%$ of Caucasians and 52\% of African-Americans reported highest levels of importance of learning about how health habits affect health risks. The higher levels of skew among African-Americans, as well as the fact that our focus is on skin cancer concerns which may have been less salient in African-Americans, led us to conduct our analyses separately by racial/ethnic group.

Table 3 presents the frequencies of the skin cancer cognitive and behavioral variables. Caucasians had higher skin cancer worry and perceived risk, and a greater occurrence of sunburn and use of sunscreen, in the past year. However, a sizable minority of African-Americans (23\%) reported somewhat or very high skin cancer worry. Caucasians and African-Americans both reported low levels of agreement that genetic factors caused skin cancer; Caucasians were more likely to agree that health habits caused skin cancer. Most participants (85\% of Caucasians; $79 \%$ of African-Americans) reported that they should improve a health habit. Yet despite reports of at least one severe sunburn in the past 12 months by $40 \%$ of Caucasians and $7 \%$ of African-Americans, almost no one reported that they should reduce their sun exposure. For CART analyses we dichotomized responses to the 2 questions (dependent variables) as: ratings of 7 (very high) versus ratings of 6 or lower. Given the imperfect relationship between genetic testing intentions and actual testing uptake, our goal was to characterize respondents selecting this extreme response (highest level of perceived importance of information-seeking regarding genes and healthhabits, respectively) since there is evidence that these respondents are most likely to follow through with genetic testing [21,38].

\section{Classification Tree Results}

Importance of Genetic Information-Seeking

For Caucasian participants, 9 variables contributed to the full tree $(\mathrm{CP}=0.01)$, and the overall classification accuracy was $82.8 \%$. The cross-validated, pruned tree had 3 levels and 4 terminal nodes (fig. 1a). Three variables remained in the model, one at each level, and the overall classification accuracy of this pruned tree remained high (79.4\%). Those reporting high or very high agreement that others close to them wanted them to learn more about keeping healthy (right branch of level 1), who were at least somewhat worried about skin cancer (right branch of level2) and had low to moderate perceived skin cancer risk (right branch of level 3) were most likely to place very high importance on genetic informationseeking. Participants with low to somewhat high agreement that others close to them wanted them to learn more about keeping healthy (left branch of level 1) tended to place lower importance on genetic informationseeking. For African-American participants, the full tree $(\mathrm{CP}=0.01)$ had 8 variables, and the overall classification accuracy was $68.4 \%$. The cross-validated, pruned tree had only one variable and 2 terminal nodes (fig. $1 \mathrm{~b}$ ), and the classification accuracy was $63.9 \%$. As with the Caucasian participants, African-American participants who reported very high agreement that others close to them wanted them to learn more about keeping healthy placed high importance on genetic information-seeking.

Importance of Health-Habit Information-Seeking

For Caucasian participants, the full tree $(\mathrm{CP}=0.01)$ included 8 variables, and the overall classification accuracy was $82.4 \%$. The pruned tree had 3 levels and 5 terminal nodes (fig. 2a), and the overall classification accuracy remained high (79.8\%). Consistent with the trees examining importance of genetic information-seeking, the most important predictor was a family factor. Those reporting very high agreement that their personal health choices affect others (right branch of level 1) and who also reported they were very familiar with their family health history (right branch of level 2) tended to place very high importance on health-habit information-seeking. Even among those who did not report very high agreement that their personal health choices affected others (left branch of level 1), those with somewhat or very high skin cancer worry (right branch of level 3) who also reported somewhat to very high agreement that others close to them wanted them to learn more about staying healthy (right branch of level 2) prioritized health-habit informationseeking.

For African-American participants, the full tree $(\mathrm{CP}=$ 0.01 ) had 6 levels, 7 variables and 9 terminal nodes (fig. 2b). The overall classification accuracy was $69.52 \%$, and the full tree was equivalent to the optimal tree with respect to cross validation relative error. Thus, no pruning was necessary. As with Caucasians, family factors figured strongly in importance placed on health-habit information-seeking. Those African-American participants who reported that social influences led them to be 
Table 3. Endorsement frequencies of skin cancer cognitions and behaviors by race

\begin{tabular}{|c|c|c|c|c|c|}
\hline \multirow[t]{2}{*}{ Predictors } & \multicolumn{2}{|c|}{$\begin{array}{l}\text { Caucasians } \\
(\mathrm{n}=732)\end{array}$} & \multicolumn{2}{|c|}{$\begin{array}{l}\text { African-Americans } \\
(\mathrm{n}=1,040)\end{array}$} & \multirow[t]{2}{*}{$\mathrm{p}$ value } \\
\hline & $\mathrm{n}$ & $\%$ & $\mathrm{n}$ & $\%$ & \\
\hline \multicolumn{6}{|l|}{ Skin cancer cognitive factors } \\
\hline Skin cancer worry & & & & & $<0.0001$ \\
\hline Low & 315 & 43.03 & 715 & 68.75 & \\
\hline Neutral & 133 & 18.17 & 88 & 8.46 & \\
\hline Somewhat high & 211 & 28.83 & 124 & 11.92 & \\
\hline Very high & 73 & 9.97 & 113 & 10.87 & \\
\hline Skin cancer perceived risk & & & & & $<0.0001$ \\
\hline Low & 417 & 57.12 & 907 & 87.55 & \\
\hline Neutral & 120 & 16.44 & 67 & 6.47 & \\
\hline Somewhat high & 175 & 23.97 & 52 & 5.02 & \\
\hline Very high & 18 & 2.47 & 10 & 0.97 & \\
\hline Genetic factors cause skin cancer & & & & & 0.32 \\
\hline Low & 360 & 49.25 & 491 & 47.30 & \\
\hline Neutral & 160 & 21.89 & 210 & 20.23 & \\
\hline Somewhat high & 181 & 24.76 & 279 & 26.88 & \\
\hline Very high & 30 & 4.10 & 58 & 5.59 & \\
\hline Health habits cause skin cancer & & & & & $<0.0001$ \\
\hline Low & 49 & 6.69 & 156 & 15.04 & \\
\hline Neutral & 70 & 9.56 & 138 & 13.31 & \\
\hline Somewhat high & 417 & 56.97 & 472 & 45.52 & \\
\hline Very high & 196 & 26.78 & 271 & 26.13 & \\
\hline \multicolumn{6}{|l|}{ Skin cancer behavioral factors } \\
\hline Severe sunburn last 12 months & & & & & $<0.0001$ \\
\hline Not at all & 442 & 60.38 & 967 & 93.07 & \\
\hline Once & 179 & 24.45 & 53 & 5.10 & \\
\hline Twice & 74 & 10.11 & 13 & 1.25 & \\
\hline More than twice & 37 & 5.05 & 6 & 0.58 & \\
\hline Sunscreen last 12 months & & & & & $<0.0001$ \\
\hline Always & 172 & 23.5 & 80 & 7.69 & \\
\hline Usually & 300 & 40.98 & 88 & 8.46 & \\
\hline Sometimes & 177 & 24.18 & 221 & 21.25 & \\
\hline Never & 83 & 11.34 & 651 & 62.60 & \\
\hline Should improve health habits & & & & & $<0.001$ \\
\hline No & 107 & 14.62 & 219 & 21.06 & \\
\hline Yes & 625 & 85.38 & 821 & 78.94 & \\
\hline Should reduce sun exposure & & & & & 0.005 \\
\hline No & 726 & 99.18 & 1,040 & 100 & \\
\hline Yes & 6 & 0.82 & 0 & 0 & \\
\hline
\end{tabular}

Skin cancer cognitive factors were recoded into 4-category variables, low (1-3), neutral (4), high (5-6), very high (7). The $\mathrm{p}$ values for all 4 -category variables are based upon $\chi^{2}$ tests with 3 degrees of freedom. The $\mathrm{p}$ values for all 2-category variables are based upon Fisher's exact tests.

highly motivated to keep healthy (right branch of level 1) placed high importance on health-habit informationseeking. Among those not highly motivated to adopt health behaviors dictated by others close to them (left branch of level 1), those who reported very high agreement regarding social influences on doing more to keep healthy (right branch of level 2) and who either strongly believed health habits cause skin cancer (right branch of level 3) or reported that they were very familiar with their family health history (right branch of level 4) also placed high importance on health-habit informationseeking. Among those who did not strongly endorse so- 


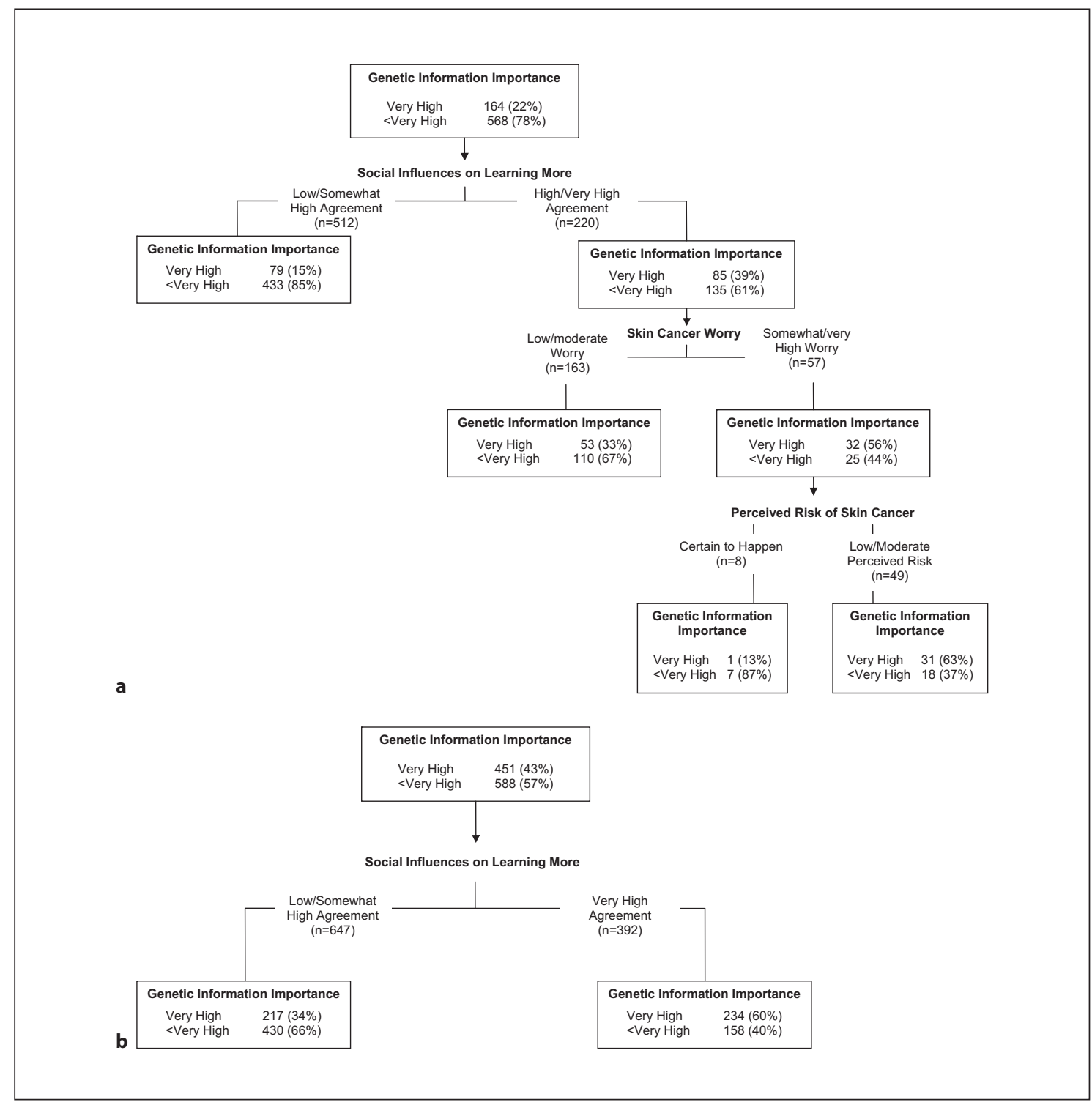

Fig. 1. Tree diagram: Importance of learning about genetics. a Caucasians $(n=732)$, pruned $1-S E$ tree, $C P=$ 0.02. b African-Americans $(n=1,039)$, pruned 1-SE tree, $C P=0.10$.

cial influences on doing more to keep healthy (left branch of level 2), most respondents generally did not place very high importance on health-habit information-seeking. Exceptions included the subset of participants who both strongly agreed their personal health choices affect others (right branch of level 3) and sought health information at least weekly (right branch of level 4), and either agreed that health habits cause skin cancer (right branch of level 5) or had somewhat or very high skin cancer worry (right branch of level 6).

\section{Comparison of Classification Tree and Logistic}

Regression Models

We compared the classification tree results to both univariate analyses (table 4) and logistic regression (LR) models by noting the variables selected and overall accuracy achieved by each approach (table 5 ). In table 4 , social influence variables were consistently highly related to the outcomes. As shown in table 5, the full trees and corresponding LRs generally contained identical variables. Notable exceptions were the inclusion of age by the trees 


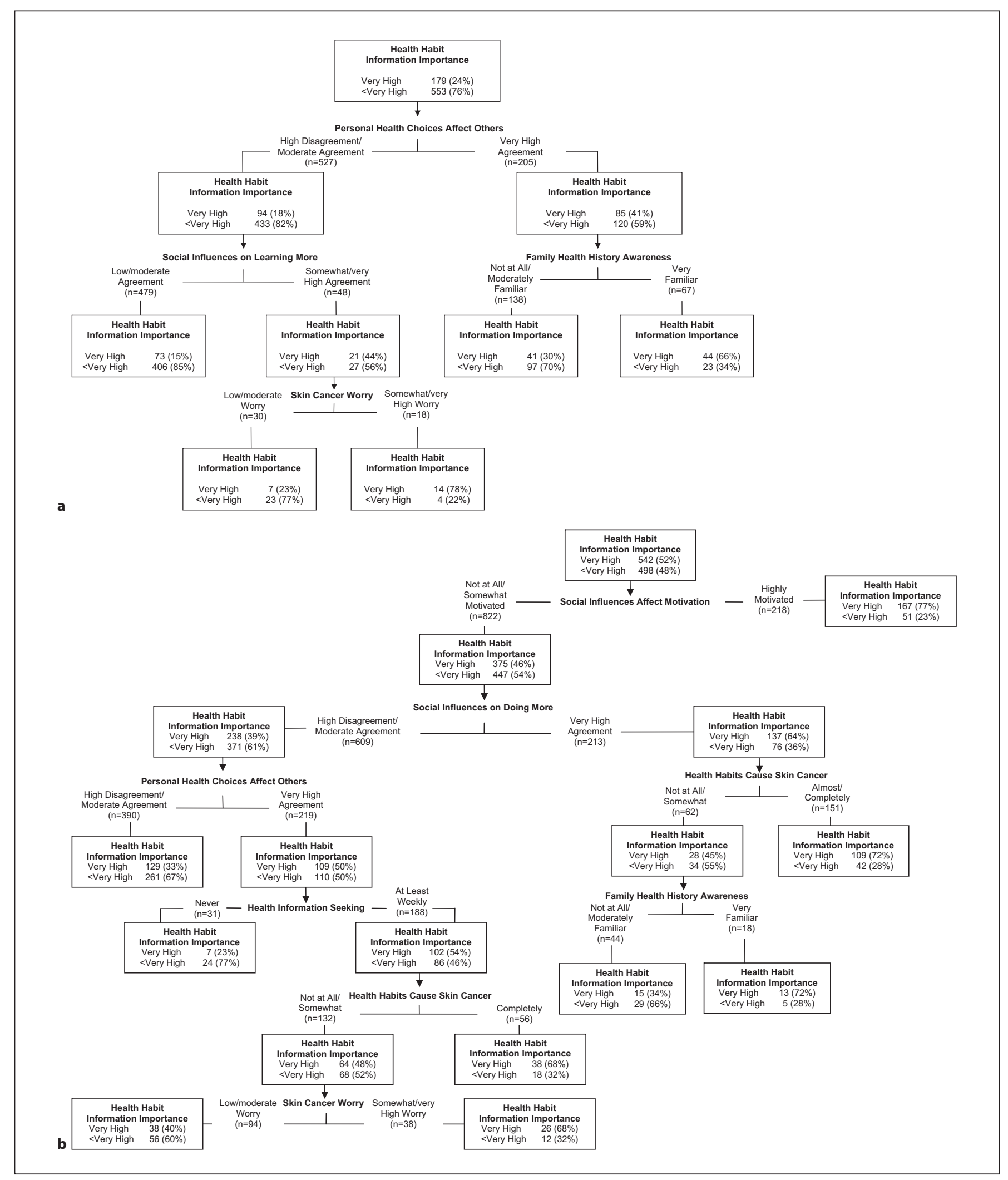

Fig. 2. Tree diagram: Importance of learning about health habits. a Caucasians $(n=732)$, pruned $1-S E$ tree, CP $=0.02$. b AfricanAmericans $(\mathrm{n}=1,040)$, pruned 1-SE tree, $\mathrm{CP}=0.10$. 
Table 4. Percent of respondents within predictor categories who endorsed high importance of genetic and behavioral information, by race

\begin{tabular}{|c|c|c|c|c|c|c|c|c|c|c|c|c|}
\hline \multirow[t]{3}{*}{ Predictors } & \multicolumn{6}{|c|}{$\begin{array}{l}\text { High genetic information importance } \\
\text { (rated } 7 \text { on scale from } 1 \text { to } 7 \text { ) }\end{array}$} & \multicolumn{6}{|c|}{$\begin{array}{l}\text { High health habit information importance } \\
\text { (rated } 7 \text { on scale from } 1 \text { to } 7 \text { ) }\end{array}$} \\
\hline & \multicolumn{3}{|c|}{ Caucasians $(\mathrm{n}=732)$} & \multicolumn{3}{|c|}{ African-Americans $(\mathrm{n}=1,040)$} & \multicolumn{3}{|c|}{ Caucasians $(\mathrm{n}=732)$} & \multicolumn{3}{|c|}{ African-Americans $(\mathrm{n}=1,040)$} \\
\hline & $\mathrm{n}$ & $\begin{array}{l}\% \text { within } \\
\text { row }\end{array}$ & $\mathrm{p}$ value & $\mathrm{n}$ & $\begin{array}{l}\text { \% within } \\
\text { row }\end{array}$ & $\mathrm{p}$ value & $\mathrm{n}$ & $\begin{array}{l}\text { \% within } \\
\text { row }\end{array}$ & $\mathrm{p}$ value & $\mathrm{n}$ & $\begin{array}{l}\% \text { within } \\
\text { row }\end{array}$ & $\mathrm{p}$ value \\
\hline \multicolumn{13}{|l|}{ Skin cancer cognitive factors } \\
\hline Skin cancer worry & & & $<0.001$ & & & $<0.001$ & & & $<0.001$ & & & $<0.001$ \\
\hline Low & 58 & 18.41 & & 284 & 39.78 & & 59 & 18.73 & & 337 & 47.13 & \\
\hline Neutral & 21 & 15.79 & & 37 & 42.05 & & 29 & 21.80 & & 50 & 56.82 & \\
\hline Somewhat high & 51 & 24.17 & & 54 & 43.55 & & 54 & 25.59 & & 68 & 54.84 & \\
\hline Very high & 34 & 46.58 & & 76 & 67.26 & & 37 & 50.68 & & 87 & 76.99 & \\
\hline Skin cancer perceived risk & & & 0.26 & & & 0.40 & & & 0.02 & & & 0.16 \\
\hline Low & 97 & 23.26 & & 387 & 42.72 & & 101 & 24.22 & & 465 & 51.27 & \\
\hline Neutral & 19 & 15.83 & & 30 & 44.78 & & 18 & 15.00 & & 35 & 52.24 & \\
\hline Somewhat high & 43 & 24.57 & & 27 & 51.92 & & 54 & 30.86 & & 34 & 65.38 & \\
\hline Very high & 3 & 16.67 & & 6 & 60.00 & & 5 & 27.78 & & 7 & 70.00 & \\
\hline Genetic factors cause skin can & cer & & 0.001 & & & $<0.001$ & & & 0.005 & & & 0.005 \\
\hline Low & 66 & 18.33 & & 193 & 39.31 & & 82 & 22.78 & & 244 & 49.69 & \\
\hline Neutral & 32 & 20.00 & & 80 & 38.10 & & 30 & 18.75 & & 95 & 45.24 & \\
\hline Somewhat high & 53 & 29.28 & & 143 & 51.44 & & 53 & 29.28 & & 165 & 59.14 & \\
\hline Very high & 13 & 43.33 & & 34 & 58.62 & & 14 & 46.67 & & 36 & 62.07 & \\
\hline Health habits cause skin cance & & & 0.04 & & & $<0.001$ & & & $<0.001$ & & & $<0.001$ \\
\hline Low & 13 & 26.53 & & 57 & 36.77 & & 11 & 22.45 & & 66 & 42.31 & \\
\hline Neutral & 17 & 24.29 & & 53 & 38.41 & & 14 & 20.00 & & 66 & 47.83 & \\
\hline Somewhat high & 78 & 18.71 & & 195 & 41.31 & & 82 & 19.66 & & 238 & 50.42 & \\
\hline Very high & 56 & 28.57 & & 146 & 53.87 & & 72 & 36.73 & & 171 & 63.10 & \\
\hline \multicolumn{13}{|l|}{ Skin cancer behavioral factors } \\
\hline Severe sunburn last 12 month & & & 0.26 & & & 0.52 & & & 0.27 & & & 0.10 \\
\hline Not at all & 106 & 23.98 & & 421 & 43.54 & & 108 & 24.43 & & 509 & 52.64 & \\
\hline Once & 34 & 18.99 & & 21 & 40.38 & & 48 & 26.82 & & 23 & 43.40 & \\
\hline Twice & 13 & 17.57 & & 4 & 30.77 & & 12 & 16.22 & & 4 & 30.77 & \\
\hline More than twice & 11 & 29.73 & & 4 & 66.67 & & 11 & 29.73 & & 5 & 83.33 & \\
\hline Sunscreen last 12 months & & & 0.26 & & & 0.18 & & & 0.54 & & & 0.16 \\
\hline Always & 42 & 24.42 & & 36 & 45.00 & & 49 & 28.49 & & 44 & 55.00 & \\
\hline Usually & 65 & 21.67 & & 29 & 32.95 & & 71 & 23.67 & & 37 & 42.05 & \\
\hline Sometimes & 33 & 18.64 & & 93 & 42.08 & & 39 & 22.03 & & 110 & 49.77 & \\
\hline Never & 24 & 28.92 & & 293 & 45.08 & & 20 & 24.10 & & 351 & 53.92 & \\
\hline Should improve health habits & & & 0.71 & & & 0.40 & & & 0.90 & & & 0.76 \\
\hline No & 22 & 20.56 & & 89 & 40.83 & & 25 & 23.36 & & 112 & 51.14 & \\
\hline Yes & 142 & 22.72 & & 362 & 44.09 & & 154 & 24.64 & & 430 & 52.38 & \\
\hline Should reduce sun exposure & & & 0.98 & & & $\mathrm{~N} / \mathrm{A}^{*}$ & & & 0.98 & & & $\mathrm{~N} / \mathrm{A}^{*}$ \\
\hline No & 163 & 22.45 & & 451 & 43.41 & & 178 & 24.52 & & 542 & 52.12 & \\
\hline Yes & 1 & 16.67 & & 0 & 0.00 & & 1 & 16.67 & & 0 & 0.00 & \\
\hline \multicolumn{13}{|l|}{ Sociodemographics } \\
\hline Age & & & 0.94 & & & 0.99 & & & 0.58 & & & 0.92 \\
\hline $25-29$ years & 26 & 22.22 & & 66 & 43.71 & & 25 & 21.37 & & 81 & 53.64 & \\
\hline 30-34 years & 45 & 23.32 & & 126 & 43.45 & & 45 & 23.32 & & 150 & 51.72 & \\
\hline $35-40$ years & 93 & 22.04 & & 259 & 43.31 & & 109 & 25.83 & & 311 & 51.92 & \\
\hline Sex & & & 0.38 & & & 0.57 & & & 0.26 & & & 0.38 \\
\hline Male & 91 & 23.82 & & 240 & 42.55 & & 100 & 26.18 & & 301 & 53.37 & \\
\hline Female & 73 & 20.86 & & 211 & 44.42 & & 79 & 22.57 & & 241 & 50.63 & \\
\hline Education & & & 0.001 & & & 0.02 & & & 0.06 & & & 0.15 \\
\hline HS diploma or less & 50 & 32.47 & & 132 & 46.81 & & 47 & 30.52 & & 158 & 55.83 & \\
\hline Some college & 52 & 23.11 & & 199 & 46.06 & & 58 & 25.78 & & 226 & 52.31 & \\
\hline College degree, post-grad & 62 & 17.56 & & 118 & 36.76 & & 74 & 20.96 & & 154 & 47.98 & \\
\hline Married/couple & & & 0.68 & & & 0.12 & & & 0.13 & & & 0.95 \\
\hline No & 41 & 23.56 & & 194 & 40.84 & & 35 & 20.11 & & 249 & 52.42 & \\
\hline Yes & 123 & 22.04 & & 257 & 45.73 & & 144 & 25.81 & & 293 & 52.04 & \\
\hline Children living in household? & & & 0.63 & & & 0.04 & & & 0.26 & & & 0.60 \\
\hline No & 46 & 21.1 & & 82 & 37.27 & & 47 & 21.56 & & 111 & 50.45 & \\
\hline Yes & 118 & 22.96 & & 469 & 45.05 & & 132 & 25.68 & & 431 & 52.56 & \\
\hline
\end{tabular}


Table 4 (continued)

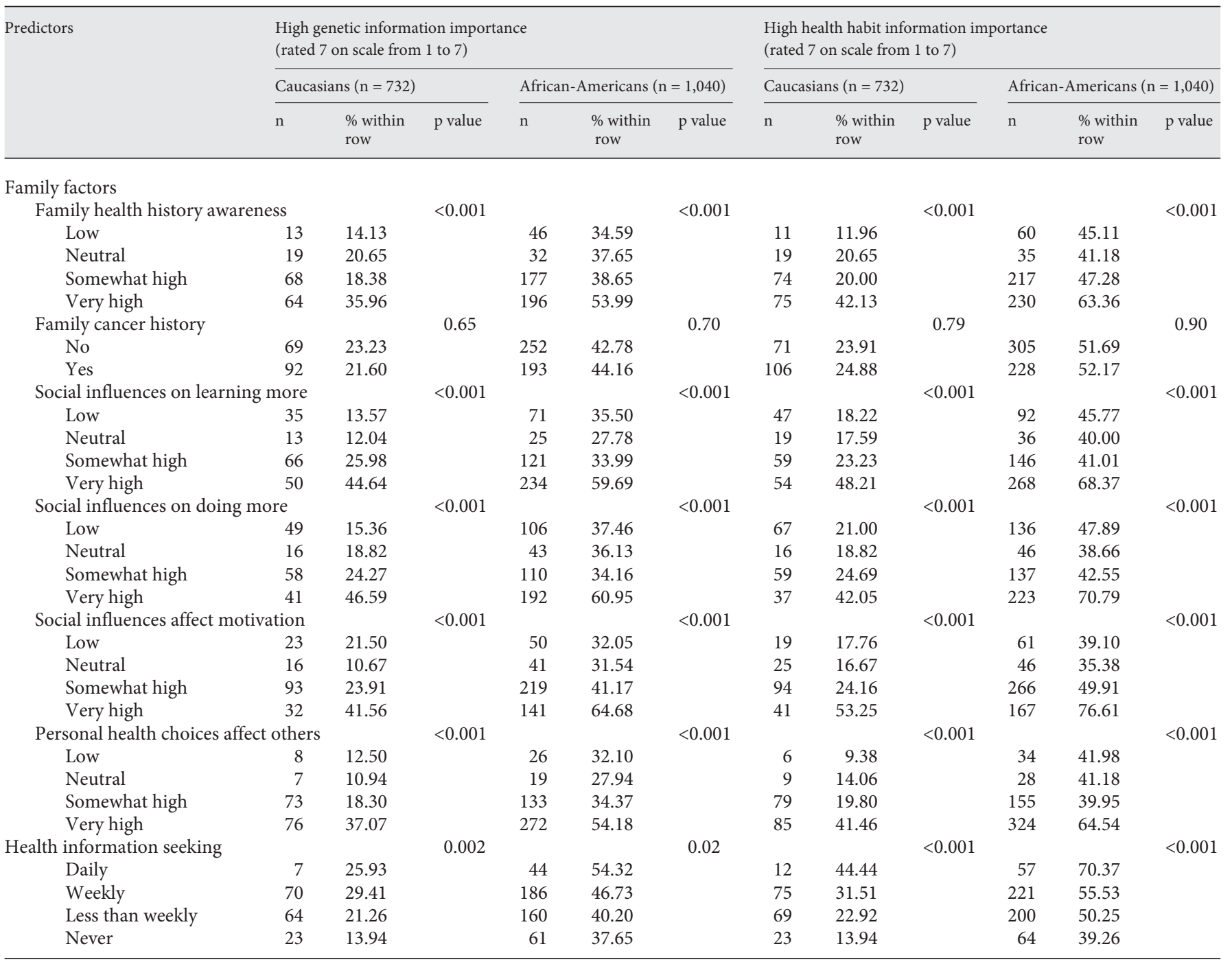

The $\mathrm{p}$ values are based on Fisher's exact tests. * Unable to calculate the p value for motivation to reduce sun exposure among African-Americans due to empty cells.

while the corresponding LR models omitted this variable. The full trees generally had higher overall accuracy than the LR models. The pruned trees were quite comparable in terms of overall accuracy to the LRs, except for the outcome genetic information importance among AfricanAmericans, where LR was somewhat more accurate. Most importantly, the pruned trees achieved these comparable accuracies but contained fewer variables and parameters (i.e. splits) to interpret. Although LR is perhaps more familiar to researchers, this familiarity comes with a loss of interpretability compared to the trees. In the LR model predicting genetic information importance among Caucasians, for example, there were 18 parameter estimates ( 3 odds ratios for each of the 6 variables in the model), plus the intercept parameter compared to only 3 splits to interpret in the corresponding pruned tree. Additionally, the trees highlighted the prominence of these social influence variables in predicting genetic and health-habit information importance, given that the first and most important split of each tree was made on a social influence variable. 


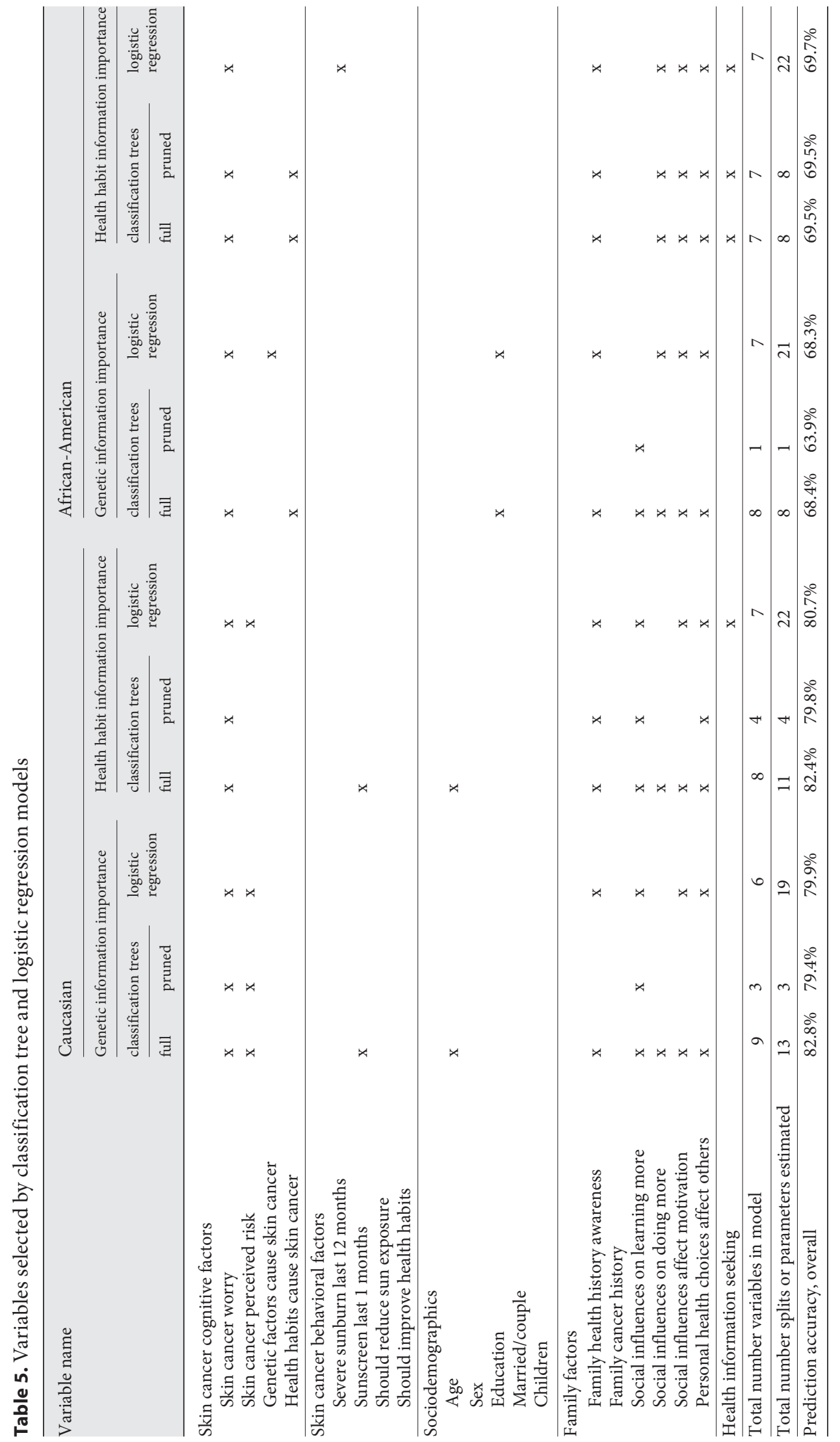




\section{Discussion}

This study is one of the first to examine skin cancer concerns and importance of genetic information-seeking in a primary care, racially/ethnically diverse population that is unselected for risk status. In the coming years, it is inevitable that awareness and demand for genetic information and testing for skin cancer and other illnesses will increase in the general population [39]. In the near future, direct-to-consumer provision of genetic testing will likely move beyond online advertising and be provided overthe-counter in drugstores nationwide, greatly increasing awareness and accessibility of these tests in diverse, general population groups. Indeed, in the past two years, the company Pathway Genomics prepared for, and then temporarily suspended, distribution of genetic test kits through drugstores nationwide after inquiries were raised by the Food and Drug Administration [40, 41]. Further research in anticipation of widespread availability of such testing is of top public health priority. One goal of our work is to identify potential avenues for heightened risk awareness, including genetic risk communication, through which diverse populations may become aware of their risks of developing melanoma and other skin cancers. The findings we report here help us anticipate the characteristics of the possible audience, or 'early responders' to genomic innovations, and who may be most likely to seek information and testing as well as directions for intervention for those who may receive genetic risk communication to maximize the psychosocial and health behavioral ramifications of such testing. Our study suggests future research needs regarding the potential motivations of genomic information-seeking.

We found promising evidence for primary care participants' receptivity to genetic and health-habit information and evidence for the salience and need for interventions to address primary care skin cancer concerns. First, we found high levels of perceived importance of genetic and health-habit information-seeking among both Caucasians and African-Americans, consistent with early-stage work examining interest in gene-environment risk information for colorectal cancer susceptibility [42]. Second, we found moderate levels of perceived skin cancer risk and worry in Caucasians, as well as some skin cancer worry in a sizable minority of African-Americans (23\%), attesting to the salience of skin cancer concerns in this primary care population. Third, we found little reported perception that participants felt they should reduce their sun exposure, despite relatively higher levels of reported severe sunburn in the past 12 months, and very mixed sunscreen use. It is important to keep in mind that the high levels of importance of genetic and health-habit information-seeking reported here may not necessarily imply high uptake levels of direct-to-consumer, or primary care-provided, genetic testing, nor are those who are interested necessarily fully aware of the complexity and uncertainty that this information will ultimately provide.

We first assessed whether skin cancer cognitive factors and behavioral factors or motivations to improve health relate to interest in learning about how genes affect personal health risks. The CART models showed that the family factors of social influences (among Caucasians and African-Americans) and skin cancer cognitive factors (among Caucasians only) were the most important predictors of perceived importance of genetic information-seeking. In both racial/ethnic groups, those who agreed that others close to them wanted them to learn more to stay healthy were also most likely to prioritize genetic information-seeking. Sociodemographic variables previously found to be important in genetic testing awareness [43] were not important predictors in this study. Among Caucasians only, high skin cancer worry, and low to moderate perceived risk of skin cancer, also dictated higher importance of genetic informationseeking. This could indicate that individuals may seek genetic information regarding their skin cancer risk regardless of behavioral factors such as sunscreen use or sunburn history, or family history of skin cancer risk. These skin cancer-specific cognitions may function differently among African-Americans, who tended to report lower levels of worry and perceived risk about skin cancer.

Of note, family factors, or social health influences, were relatively more important predictors of higher levels of importance of genetic information-seeking than skin cancer behavioral factors. Our findings are highly consistent with the Theory of Planned Behavior [44], given that subjective norms - both normative beliefs about learning and doing more to keep healthy, as well as perceived motivation to comply with what close others think is important - represent an important precursor and determinant of behavioral intentions and adoption. We believe there are 3 valuable implications of these findings. First, these findings point out that desires for health risk information may trump actual cancer risk status in motivating patients' - as well as physicians' - pursuit of genetic information. This has been shown to be the case of testing for high-risk mutations, as well [45], and represents an important area for future investigation as genetic testing be- 
comes more affordable and available to individuals without specific health risk factors. Second, communication, problem-solving and social influences regarding health at the level of the family or kinship network is likely an important, underresearched topic that is highly relevant to genetic information-seeking. It has been recently noted that responses to genetic risk are affected by factors at the family or kinship network - including provision and appraisal of risk information, coping with the uncertainty of genetic risk as well as motivational strategies for healthy behavior change [46]; the current work has implications for family factors in the potential uptake of genetic risk information, as well. Family support and communication regarding establishing and maintaining good health may provide important groundwork for genetic informationseeking across a broad range of socioeconomic categories, given that such support may lead to explicit or implied social influences on health information-seeking. Finally, the measures used in the current study assessed individual-level cognitions, which in light of our familylevel findings highlight the continued need for alternative, complimentary research strategies such as social network analysis. Given the anticipated availability of genetic susceptibility testing via medical and direct-to-consumer access points, examination of these multiple individual and familial motives for testing, as well as the perceived value of genetic information, deserves further study. These social motives may be important elements of the perceived personal utility of genetic and health-habit information in many people, and so interventions developed to help individuals make the most of their risk feedback findings might usefully address the social contextual implications of any recommended health behavior changes. Importantly, this highly contextualized, collectivist perspective may be culturally consonant with diverse population subgroups including African-Americans.

Finally, we assessed whether skin cancer cognitive factors and behavioral factors or motivations to improve health relate to interest in learning about how health habits affect personal health risks. Perceived importance of health-habit information-seeking, like perceived importance of genetic information-seeking, was consistently associated with family factors, consistent with the Theory of Planned Behavior [44]. For instance, participants' belief that their personal health choices affect others who are close to them was the most important predictor of health-habit information-seeking in Caucasians; high motivation to do what others close to them want them to do to keep healthy was the most important predictor of health-habit information-seeking in African-Americans. As well, other family factors figured strongly in prioritization of health-habit information-seeking in both racial/ ethnic groups. Interestingly, awareness of family health history was a prominent predictor of high importance of health-habit, but not genetic, information-seeking. Efforts to increase awareness of family health history may increase the salience of those health habits that have led to common illnesses in their family members; this dictates the need to examine cognitive and communication outcomes in studies seeking to provide family history information to primary care individuals.

We have used the CART method in this study to emphasize interactions that clearly identify participant subgroups that are most homogenous on our outcome variables. This approach achieves greater parsimony; while the cost involves some reduction in classification accuracy in comparison with a logistic regression approach, we argue that the current study is ideally suited to a CART approach since we examined a relatively large number of potential predictors that were anticipated to be correlated with each other [23].

There are limitations to the current work. First, our study was cross-sectional, and the outcome variables were self-reported rather than behavioral assessments of genetic information-seeking. African-American participants may have been unaware of their skin cancer risk and thus less likely to report worry and perceived risk about this malignancy. The outcome variables were not skin cancer-specific, indicating the need for further work to confirm these findings as it is possible that those with higher behavioral risks, perceived risks or worries may place high importance on skin cancer risk (genetic and health-habit) information-seeking, even if they do not prioritize genetic and health-habit information-seeking overall. A latent general health interest factor may drive both outcome variables given that they were highly correlated. Finally, genetic information-seeking may not dictate ultimate genetic testing, necessitating further work to examine testing uptake in primary care.

We conclude that based on our findings, the likely audience for genomic innovations is likely to be widely distributed over general population subgroups and that motives for genetic information-seeking may have more to do with social health influences than skin cancer-specific behavioral risks or skin cancer perceived risks and worries, per se. These motives may help shape the perceived value, or personal utility, of risk information related to emerging genomic innovations, and will likely be operative when those tested consider behavioral responses to 
such risk information, providing a set of foci for useful intervention development, including vehicles to enhance the social and familial implications of behavioral risk reduction in response to genetic risks.

\section{Acknowledgments}

Preparation of this manuscript was supported by National Institutes of Health grants CA98106, CA133376 and CA137532 to Jennifer Hay and Weill Cornell Medical College Clinical and Translational Science Award support for Yuelin Li (NIH UL1RR024996). We also acknowledge the invaluable assistance of Susan Gall and Marcel Ramos in the preparation of this paper. This research was supported by the Intramural Research Program of the National Human Genome Research Institute at the National Institutes of Health in Bethesda, Maryland (USA). However, the proposed research was made possible by collaboration with the Cancer Research Network funded by the National Cancer Institute (U19 CA 079689). Additional resources were provided by the Cancer Research Network, Group Health Research Institute and Henry Ford Hospital. Genotyping services were provided by the Center for Inherited Disease Research (CIDR). CIDR is fully funded through a federal contract from the National Institutes of Health to The Johns Hopkins University (HHSN268200782096C). We also thank the Multiplex steering committee members (Drs. Colleen McBride, Larry Brody, Andy Baxevanis, Robert Reid, Eric Larson, and Sharon Kardia) for their critical review of this paper. Our thanks also go to the study participants who were all members of the Henry Ford Health System.

\section{References}

1 Lander ES, Linton LM, Birren B, Nusbaum $\mathrm{C}$, Zody MC, et al: Initial sequencing and analysis of the human genome. Nature 2001; 409:860-921.

-2 Khoury MJ, McBride CM, Schully SD, Ioannidis JP, Feero WG, Janssens AC, Gwinn M, Simons-Morton DG, Bernhardt JM, Cargill M, Chanock SJ, Church GM, Coates RJ, Collins FS, Croyle RT, Davis BR, Downing GJ, Duross A, Friedman S, Gail MH, Ginsburg GS, Green RC, Greene MH, Greenland P, Gulcher JR, Hsu A, Hudson KL, Kardia SL, Kimmel PL, Lauer MS, Miller AM, Offit K, Ransohoff DF, Roberts JS, Rasooly RS, Stefansson K, Terry SF, Teutsch SM, Trepanier A, Wanke KL, Witte JS, Xu J: The scientific foundation for personal genomics: recommendations from a National Institutes of Health-Centers for Disease Control and Prevention multidisciplinary workshop. Genet Med 2009;11:559-567.

>3 Lerman C, Croyle RT, Tercyak KP, Hamann $\mathrm{H}$ : Genetic testing: psychological aspects and implications. J Consult Clin Psychol 2002;70:784-797.

4 Patenaude AF, Guttmacher AE, Collins FS: Genetic testing and psychology. New roles, new responsibilities. Am Psychol 2002;57: 271-282.

5 McBride CM, Brody LC: Point: genetic risk feedback for common disease time to test the waters. Cancer Epidemiol Biomarkers Prev 2007;16:1724-1726.

6 Freimuth V: Educating the public; in Hernandez L (ed): Implications of Genomics for Public Health: Workshop Summary. Washington, D.C., Institute of Medicine, the National Academies Press, 2005, p 37.
7 Hay J, Meischke H, Bowen D, Mayer J, Shoveller J, Press N, Berwick M, Burke W: Anticipating dissemination of cancer genomics in public health: a theoretical approach to novel psychosocial and behavioral challenges. Ann Behav Med 2007;34:275-286.

8 American Cancer Society: Cancer facts and figures 2009. http://www.cancer.org/Research/CancerFactsFigures/cancer-factsfigures-2009.

-9 Geller AC, Miller DR, Annas GD, Demierre MF, Gilchrest BA, Koh HK: Melanoma incidence and mortality among us whites, 19691999. JAMA 2002;288:1719-1720.

10 Linos E, Swetter SM, Cockburn MG, Colditz GA, Clarke CA: Increasing burden of melanoma in the United States. J Invest Dermatol 2009;129:1666-1674.

11 Zell A, Cinar P, Mobasher M, Ziogas A, Meyskens F, Anton-Culver H: Survival for patients with invasive cutaneous melanoma among ethnic groups: the effects of socioeconomic status and treatment. J Clin Oncol 2008;26:66-75.

12 Byrd-Miles K, Toombs E, Peck G: Skin cancer in individuals of African, Asian, LatinAmerican and American-Indian descent: differences in incidence, clinical presentation and survival compared to Caucasians. J Drugs Dermatol 2007;6:10-16.

$13 \mathrm{Hu}$ S, Soza-Vento R, Parker D, Kirsner R: Comparison of stage at diagnosis of melanoma among Hispanic, black, and white patients in Miami-Dade County, Florida. Arch Dermatol 2006;142:704-708.

-14 Rouhani P, Hu S, Kirsner R: Melanoma in Hispanic and black Americans. Cancer Control 2008; 15:248-253.

- 15 Bradford PT, Goldstein AT, McMaster ML, Tucker MA: Acral lentiginous melanoma: incidence and survival patterns in the United States, 1986-2005. Arch Dermatol 2009; 145:427-434.
6 Berwick M: Gene-environment interaction in melanoma. Forum (Genova) 2000;10:191200.

17 Pho L, Grossman D, Leachman SA: Melanoma genetics: a review of genetic factors and clinical phenotypes in familial melanoma. Curr Opin Oncol 2006;18:173-179.

18 Tucker MA, Goldstein AM: Melanoma etiology: where are we? Oncogene 2003;22:30423052.

19 Raimondi S, Sera F, Gandini S, Iodice S, Calini S, Maisonneuve P, Fargnoli MC: MC1R variants, melanoma and red hair color phenotype: a meta-analysis. Int J Cancer 2008; 122:2753-2760.

20 John PR, Makova K, Li WH, Jenkins T, Ramsay M: DNA polymorphism and selection at the melanocortin-1 receptor gene in normally pigmented southern African individuals. Ann NY Acad Sci 2003;994:299-306.

21 McBride CM, Alford SH, Reid RJ, Larson EB, Baxevanis AD, Brody LC: Characteristics of users of online personalized genomic risk assessments: implications for physician-patient interactions. Genet Med 2009;11:582587.

22 Breiman L, Friedman JH, Olshen RA, Stone CJ: Classification and Regression Trees. New York, Chapman Hall/CRC, 1984.

23 Lemon SC, Roy J, Clark MA, Friedmann PD, Rakowski W: Classification and regression tree analysis in public health: methodological review and comparison with logistic regression. Ann Behav Med 2003;26:172-181.

24 Griffin RJ, Dunwoody S, Neuwirth K: Proposed model of the relationship of risk information seeking and processing to the development of preventive behaviors. Environ Res 1999;80:S230-S245. 
25 Hensley Alford S, McBride CM, Reid RJ, Larson EB, Baxevanis AD, Brody LC: Participation in genetic testing research varies by social group. Public Health Genomics 2011;14 85-93.

26 Hastie T, Tibshirani R, Friedman J: The Elements of Statistical Learning: Data mining, Inference, and Prediction. New York, Springer, 2001.

27 Strobl C, Malley J, Tutz G: An introduction to recursive partitioning: rationale, application, and characteristics of classification and regression trees, bagging, and radom forests. Psychol Methods 2009;14:323-348.

28 Florez-Lopez R, Ramon-Jeronimo JM: Marketing segmentation through machine learning models: an approach based on customer relationship management and customer profitability accounting. Social Science Computer Review. http://ssc.sagepub.com/ cgi/content/abstract/0894439308321592v1 (accessed February, 2010).

29 Conner BT, Hellemann GS, Ritchie TL, Noble EP: Genetic, personality, and environmental predictors of drug use in adolescents. J Subst Abuse Treat 2010;38:178-190.

30 King AC, Ahn DF, Atienza AA, Kraemer HC: Exploring refinements in targeted behavioral medicine intervention to advance public health. Ann Behav Med 2008;35:251-260.

-31 King AC, Marcus B, Ahn D, Dunn AL, Rejeski WJ, Sallis JF, Coday M: Identifying subgroups that succeed or fail with three levels of physical activity intervention: the activity counseling trial. Health Psychol 2006;25: 336-347.
2 Lemon SC, Zapka J, Li W, Estabrook B, Rosal M, Magner R, Andersen V, Borg A, Hale J: Step ahead a worksite obesity prevention trial among hospital employees. Am J Prev Med 2010;38:27-38.

33 Calvocoressi L, Stolar M, Kasl SV, Claus EB, Jones BA: Applying recursive partitioning to a prospective study of factors associated with adherence to mammography screening guidelines. Am J Epidemiol 2005;162:12151224.

34 Therneau TM, Atkinson EJ: An introduction to recursive partitioning using the rpart routines. Rochester, Mayo Foundation, 1997.

35 Feldesman MR: Classification trees as an alternative to linear discriminant analysis. Am J Phys Anthropol 2002;119:257-275.

36 Radespiel-Tröger M, Hohenberger W, Reingruber B: Improved prediction of recurrence after curative resection of colon carcinoma using tree-based risk stratification. Cancer 2004;100:958-967.

37 Venables WN, Ripley BD: Modern Applied Statistics with S, ed 4, New York, Springer, 2002.

- 38 Sanderson SC, O’Neill SC, Bastian LA, Bepler G, McBride CM: What can interest tell us about uptake of genetic testing? Intention and behavior amongst smokers related to patients with lung cancer. Public Health Genomics 2010;13:116-124.

39 Hansen CB, Wadge LM, Lowstuter K, Boucher K, Leachman SA: Clinical germline genetic testing for melanoma. Lancet Oncol 2004; $5: 314-319$.
40 Pollack A: Start-up may sell genetic tests in stores.http://www.nytimes.com/2010/05/11/ health/11gene.html. The New York Times, May 11, 2010.

41 Pollack A: Walgreens delays selling genetic test kit. http://www.nytimes.com/2010/05/ 13/health/13gene.html?scp=18sq=walgreen s+delays+selling+personal+genetic\&st=nyt.

42 Myers RE, Weinberg DS, Manne SL, Sifri R, Cocroft J, Kash K, Wilfond B: Genetic and environmental risk assessment for colorectal cancer risk in primary care practice settings: a pilot study. Genet Med 2007;9:378-384.

43 Pagan JA, Su D, Li L, Armstrong K, Asch DA: Racial and ethnic disparities in awareness of genetic testing for cancer risk. Am J Prev Med 2009;37:524-530.

44 Montano D, Kasprzyk D: The theory of reasoned action and the theory of planned behavior; in Glanz K, Rimer BK, Lewis FM (eds): Health Behavior and Health Education: Theory, Research, and Practice. San Francisco, Jossey-Bass, 2002, pp 67-98

45 White DB, Bonham VL, Jenkins J, Stevens N, McBride CM: Too many referrals of low-risk women for $B R C A 1 / 2$ genetic services by family physicians. Cancer Epidemiol Biomarkers Prev 2008;17:2980-2986.

46 McBride CM, Koehly LM, Sanderson SC, Kaphingst KA: The behavioral response to personalized genetic information: will genetic risk profiles motivate individuals and families to choose more healthful behaviors? Annu Rev Public Health 2010;31:89103

\section{Erratum}

In the article 'Skin Cancer Concerns and Genetic Risk Information-Seeking in Primary Care' by Hay et al. (Public Health Genomics DOI: $10.1159 / 000330403$ ) there is an inaccuracy in table 2.

In table 2, descriptive statistics (n, \%) for marital status and parenthood status were reversed. Accordingly, 76\% of Caucasians and 54\% of African-Americans were married or in a couple; $70 \%$ of Caucasians and $79 \%$ of African-Americans had children. 